\title{
FORMULATION AND EVALUATION OF CONTROLLED DELIVERY FLOATING MICROSPHERES OF RANITIDINE HYDROCHLORIDE
}

Ahmed Samy ${ }^{1}$, Mamdouh Ghorab ${ }^{2}$, Shadeed Gad ${ }^{2,3}$ and Nashwa Hassan ${ }^{3}$

1 Department of pharmaceutics, Faculty of Pharmacy, Al Azhar University, Egypt.

2 Department of pharmaceutics, Faculty of Pharmacy, Suez Canal University, Ismailia, Egypt.

3 Department of Pharmaceutics, Faculty of Pharmacy and Pharmaceutical Industries, Sinai University, El-Arish, North Sinai, Egypt

\begin{abstract}
Aim: the objective of the present paper was to design and formulate Ranitidine hydrochloride $(\mathrm{RH})$ floating microspheres by the emulsion solvent evaporation technique using different polymers: [Ethyl cellulose (EC) and Eudragit E100 (E E100)] with different drug: polymer ratio and at different speeds of rotation.

Methodology: the emulsion solvent- evaporation technique was used for the preparation of Ranitidine floating microspheres. The prepared microspheres were examined for their production yield, entrapment efficiency, micromeritic properties, in- vitro buoyancy and invitro drug release.

Results and discussion: Evaluation of micromeretics properties of the prepared microspheres showed that all formulae have good flow properties. The production yield of the microspheres ranging from $60.7 \%$ to $98.7 \%$ [the best one was (RH-EC/E E100 $(1: 2.5) 400 \mathrm{rpm})]$ and encapsulation efficiencies ranging from $47.5 \%$ to $79.7 \%$ [the best one was (RH-EC (1:4)400 rpm)].Microspheres showed excellent buoyancy ranging from $72 \%$ to $92 \%$ over $12 \mathrm{hr}$ [the best one was (RH-E E100 (1:1)400 rpm)] as RH microspheres with low density showed excellent floatation behavior than others with high density. In vitro release of the drug showing a biphasic pattern with controlled release during 12 hours. The release of $\mathrm{RH}$ increased as the concentration of polymer decreased. By combining the production yield, micromeretics parameters, entrapment efficiency and the in vitro release of $\mathrm{RH}$ from capsules, it was found that RH-EC/E E100 (1:2.5) $400 \mathrm{rpm}$ was superior to all of the prepared formulae.
\end{abstract}

Key words: RH (Ranitidine hydrochloride), EC (Ethyl cellulose) and E E100 (Eudragite E100).

\section{INTRODUCTION}

Drug absorption from oral controlled release (CR) dosage forms is often limited by the short gastrointestinal retention time, available for absorption. Floating drug delivery systems are among the several approaches that have been developed in order to increase the gastric residence time of the dosage forms Singh et al., (2011).The multiple unit system has been developed to identify the merit over a single unit dosage form because the single unit. Floating systems are more popular but have a disadvantage of their "all or none" emptying process because of high variability of the gastrointestinal transit time. The synthetic polymer has been used to prepare floating microspheres. The present study was based on floating microspheres of both hydrophilic and acrylic polymers using Ranitidine hydrochloride (RH) as a model drug. It is an anti ulcer drug that has been widely used in treating gastric and duodenal ulceration and also in Zollinger Ellison syndrome. It is poorly absorbed from the lower GIT and has a short elimination half life of 2-3 hours and a bioavailability of 50\% Mastiholimath et al., (2008). 
One the other hand, EC the ethyl ether of cellulose, is a long chain polymer of anhydroglucose units joined together by acetal linkages. It is generally considered a nontoxic, biocompatible as well as non-biodegradable polymer. These characteristics are the reasons for its extensive use in the development of oral dosage forms, especially sustained release formulations, including oral multi-unit dosage forms (i.e., microparticles) Rowe $\boldsymbol{e}$ al., (2003).whereas, E E100 the hydrophobic polymer which prolongs the release of watersoluble and water insoluble drugs from its matrices.

Ranitidine hydrochloride is an $\mathrm{H} 2$ receptor antagonist, with a short half-life and a low oral bioavailability of $50 \%$, was selected as a model drug to formulate a controlled release formulation with improved oral bioavailability, by prolonging the gastric residence time.

The Emulsion-Solvent Evaporation method has been widely used and several modifications of it have been successfully employed for the encapsulation of drugs for that purpose.

\section{EXPERIMENTAL PART} Materials

Ranitidine hydrochloride (RH), kindly donated by Medical Union Pharmaceuticals, Abu-Sultan, Ismailia, Egypt); Ethyl cellulose (EC) (BIO BASIC INC, Markham, Ontario3R1G6, Canada); Eudragit E 100(E E100) (Rohm Pharma GMBH 50.277 1-243 Germany); N-Hexane, Acetone, Heavy liquid paraffin, Hydrochloric acid (pure lab. Chemicals, USA, El-Nasr chemical company, Cairo, Egypt); Sorbitan Monooleate (Span 80), Cuangdong Uanghua Chemical Co., India. All other chemicals were analytical reagent grades.

\section{Equipment}

Shimadzu double beam UV- visible spectrophotometer model (2401/PC), (Japan); Dissolution Tester, six-cup model, Erweka Apparatebau GmbH,(Germany); Magnetic stirrer with hot plate (Brandstead /Thermolyne, 50/60HZ, 220-240 volts, Dubuque /Iowa 52001 U.S.A); Electric balance, SARTORIUS AG, (Germany); Oven, Binder GmbH Bergstr. 14 D78532 Tuttlingen / Germany; pH meter, JENWAY Designed and manufactured in the EU by Barloworld Scientific Ltd, Dunnlow, Essex, CM6 3LB (England); Shimadzu 435 U-O4 IR spectrometer, (Japan) and Differential scanning calorimeter Shimadzu DSC-50, (Japan).

\section{Methodology}

\section{1-Preparation of Microspheres}

RH Microspheres were prepared by the emulsion-solvent evaporation technique .The external phase was prepared by addition of (1\%) Span 80 in heavy liquid paraffin. The polymers used (EC or E E100) were dissolved in acetone until clear solution was obtained. The required amount of the drug was then added to obtain the internal phase. The external phase was mixed with the internal phase to carry out the emulsification process. Acetone was allowed to evaporate by continuous stirring at different speeds and then at room temperature using magnetic stirrer. Stirring was continued at room temperature until complete evaporation of the solvent, (about 5 hours). Liquid paraffin was decanted and the microspheres produced were filtered off, washed three times with $n$-hexane $(3 \times 50 \mathrm{ml})$ to remove the remaining oily phase and then dried over night at room temperature $\left(25^{\circ} \mathrm{C}\right)$.

Optimization of microspheres formulation using factorial design (Box-Behnken design) based on the preliminary trials, optimization was carried out by the 3 level factorial design to produce the desirable effective percent drug entrapment and a sustained drug release pattern over 12 hours .The optimization of the floating microspheres was carried out by taking into consideration the type of polymer used, the amount of polymer and the stirring rate (RPM) as formulation variables and the percentage drug entrapment and the in vitro drug release at different times( $2 \mathrm{hr}-6 \mathrm{hr}-12 \mathrm{hr})$ as responses. The relationship between the 
process variables and the responses were evaluated by the 3 level full factorial design and response surface methodology (Brijesh et al., 2004; Jayavadhan et al., 2010)

The suggested formulae of Ranitidine hydrochloride were tabulated in Table (1).

\section{2-Determination of the production yield of RH microspheres}

The production yield which a measure of the actual weight of the prepared microspheres (drug + polymer + any other additives). This value was calculated by dividing the actual weight of the prepared RH microspheres by the theoretical weight. Thus, the dried microspheres were weighted to determine the production yield $(\%)$ of the recovered microspheres using the equation: (El-Kamel et al., 2006).

$$
\text { Yield } \%=\frac{\text { Weight of the collected microspheres }}{\text { Total weight of drug and polymer used }} \quad \text { x } 100
$$

\section{3-Determination of the entrapment efficiency in the prepared microspheres}

The entrapment efficiency of RH microspheres was determined in $0.1 \mathrm{~N} \mathrm{HCl}$ by the following method:

A weighed quantity of microspheres equivalent to $100 \mathrm{mg}$ of the pure drug was taken in $100 \mathrm{ml}$ volumetric flask and dissolved in $0.1 \mathrm{~N} \mathrm{HCl}$ using sonication for $5 \mathrm{~min}$ and the volume was made up to $100 \mathrm{ml}$ with $0.1 \mathrm{~N} \mathrm{HCl}$. The solution was then filtered through $(0.45$ $\mu \mathrm{m}$ membrane filter). The absorbance was measured after suitable dilutions with $0.1 \mathrm{~N} \mathrm{HCl}$ solutions at $312.6 \mathrm{~nm}$ by using $0.1 \mathrm{~N} \mathrm{HCl}$ as blank. All analyses were carried out in triplicates

\section{4-Micromeritic properties of the prepared $\mathrm{RH}$ microspheres}

The prepared microspheres were evaluated through determination of the following parameters:

\section{a- Densities of microspheres}

Both loose bulk density $\left(D_{b}\right)$ and tapped bulk density $\left(D_{t}\right)$ were determined. A quantity of $10 \mathrm{~g}$ microspheres from each batch was introduced into a $10 \mathrm{ml}$ measuring cylinder. The initial volume was observed, and then the cylinder was allowed to stroke. The tapping was continued until no further change in volume was noted. LBD and TBD were calculated using the following formulas (Tayade and Kale, 2004):

\section{b- Hausner Ratio}

$$
\begin{aligned}
& \mathrm{D}_{\mathrm{b}}=\mathrm{Wt} / \text { bulk volume }=\mathrm{W} / \mathrm{V}_{\mathrm{b}} \\
& \mathrm{D}_{\mathrm{t}}=\mathrm{Wt} / \text { tapped volume }=\mathrm{W} / \mathrm{V}_{\mathrm{t}}
\end{aligned}
$$

It is the ratio between bulk density and tapped density. It gives an idea about the flow characters of powder particles (Kumar et al., 2002).

Hausner ratio $=\mathrm{D}_{\mathrm{t} /} \mathrm{D}_{\mathrm{b}}$

\section{c- Compressibility percent (Car's Index)}

Compressibility is indirectly related to the relative flow rate, cohesiveness, and particle size of a powder. The compressibility percent of a material can be estimated as (Staniforth, 2002) :

\section{d- Angle of Repose}

$$
\text { Compressibility } \%=\left(\mathrm{D}_{\mathrm{t}-} \mathrm{D}_{\mathrm{b}} / \mathrm{D}_{\mathrm{t}}\right) \times 100
$$

It was measured by passing the microspheres through a funnel which was maintained at a fixed height in all experiments. The height (h) and radius (r) of the cone were determined. The angle of repose is calculated from the equation (Sajeev et al., 2002; Shariff et al., 2007).

$$
\operatorname{Tan} \theta=\mathrm{h} / \mathrm{r}
$$

\section{5-In-vitro buoyancy of RH microspheres}

The floating microspheres $(100 \mathrm{mg})$ were spread over the surface of the dissolution medium (simulated gastric fluid, SGF, $\mathrm{pH}$ (1.2) that was agitated by a paddle rotating at 100 
rpm. After agitation for the predetermined time interval, the microspheres floating over the surface of the medium and those settled at the bottom of the flask were recovered separately, deried, weighed and their buoyancy was calculated by the following equation Singh $\boldsymbol{e t}$ al., 2011)

Buoyancy $(\%)=\mathrm{Q}_{f} /\left(\mathrm{Q}_{f+} \mathrm{Q}_{\mathrm{s}}\right)$

Where $\mathrm{Q}_{f}$ and $\mathrm{Q}_{s}$ are the weight of the floating and the settled microspheres respectively

\section{6-In-vitro Release Study}

The in-vitro release of $\mathrm{RH}$ from the prepared microspheres as well as from hard gelatin capsules filled with known amount of microspheres (equivalent to $100 \mathrm{mg}$ of $\mathrm{RH}$ ) was carried out at $37 \pm 0.5{ }^{\circ} \mathrm{C}$ for 12 hours, using apparatus II.The baskets were rotated at 100rpm. The dissolution medium was $900 \mathrm{ml} 0.1 \mathrm{~N} \mathrm{HCl} \mathrm{pH} \mathrm{1.2.} 5 \mathrm{ml}$ samples were withdrawn replaced with fresh medium at each appropriate time intervals. The drug content in the filtered samples was measured spectrophotometrically at $312.6 \mathrm{~nm}$ (Singh et al., 2011) after suitable dilutions. The release experiments were repeated in triplicates.

Table (1): Composition of Different Suggested Formulae of Ranitidine Hydrochloride Microspheres Using Ethyl cellulose and Eudragit E100

\begin{tabular}{|l|c|c|c|c|c|c|c|}
\hline \multicolumn{1}{|c|}{ Formula No. } & $\begin{array}{c}\text { RH } \\
(\mathbf{m g})\end{array}$ & $\begin{array}{c}\text { Mg St } \\
(\mathbf{m g})\end{array}$ & $\begin{array}{c}\text { EC } \\
(\mathbf{m g})\end{array}$ & $\begin{array}{c}\text { E } \\
\mathbf{E 1 0 0} \\
(\mathbf{m g})\end{array}$ & $\begin{array}{c}\text { Span } \\
\mathbf{8 0}\end{array}$ & $\begin{array}{c}\text { D:P } \\
\text { Ratio }\end{array}$ & $\begin{array}{c}\text { Speed } \\
(\mathbf{r p m})\end{array}$ \\
\hline RH - EC (1:2.5) 300 rpm & 500 & 500 & 1250 & - & $1 \%$ & $1: 2.5$ & 300 \\
\hline RH - EC/E E 100 (1:2.5) 400 rpm & 500 & 500 & 625 & 625 & $1 \%$ & $1: 2.5$ & 400 \\
\hline RH - EC/E E 100 (1:2.5) 400 rpm & 500 & 500 & 625 & 625 & $1 \%$ & $1: 2.5$ & 400 \\
\hline RH - EC (1:1) 400 rpm & 500 & 500 & 500 & - & $1 \%$ & $1: 1$ & 400 \\
\hline RH - E E 100 (1:1) 400 rpm & 500 & 500 & - & 500 & $1 \%$ & $1: 1$ & 400 \\
\hline RH - E E 100 (1:2.5) 500 rpm & 500 & 500 & - & 1250 & $1 \%$ & $1: 2.5$ & 500 \\
\hline RH - EC/E E100 (1:4) 500 rpm & 500 & 500 & 1000 & 1000 & $1 \%$ & $1: 4$ & 500 \\
\hline RH - EC/E E100 (1:1) 300 rpm & 500 & 500 & 250 & 250 & $1 \%$ & $1: 1$ & 300 \\
\hline RH - E E 100 (1:4) 400 rpm & 500 & 500 & - & 2000 & $1 \%$ & $1: 4$ & 400 \\
\hline RH - E E 100 (1:2.5) 300 rpm & 500 & 500 & - & 1250 & $1 \%$ & $1: 2.5$ & 300 \\
\hline RH - EC/E E100 (1:1) 500 rpm & 500 & 500 & 250 & 250 & $1 \%$ & $1: 1$ & 500 \\
\hline RH - EC/E E100 (1:4) 300 rpm & 500 & 500 & 1000 & 1000 & $1 \%$ & $1: 4$ & 300 \\
\hline RH - EC (1:4) 400 rpm & 500 & 500 & 2000 & - & $1 \%$ & $1: 4$ & 400 \\
\hline RH - EC/EE 100 (1:2.5) 400 rpm & 500 & 500 & 625 & 625 & $1 \%$ & $1: 2.5$ & 400 \\
\hline RH - EC (1:2.5) 500 rpm & 500 & 500 & 1250 & - & $1 \%$ & $1: 2.5$ & 500 \\
\hline
\end{tabular}

\section{RESULTS AND DISCUSSION}

The wave length of maximum absorbance of $\mathrm{RH}$ in $0.1 \mathrm{~N} \mathrm{HCl}$ was found to be 312.6 nm. The calibration curve of RH obeyed Beer's Lambert law.

\section{Production yield of RH microspheres}

The range of the production yield of the prepared $\mathrm{RH}$ microspheres found to be between $60.66 \%$ and $98.68 \%$ as shown in table (2). The highest value appeared in the formula R H - EC/E E 100 (1:2.5) $400 \mathrm{rpm}$ (98.68\%) while the lowest value appeared in formula R H - E E 100 (1:1) $400 \mathrm{rpm}(60.66 \%)$.

Consequently, the RH microspheres can be arranged in descending order concerning their production yield above $90 \%$ as follows: RH - EC/E E 100 (1:2.5) $400 \mathrm{rpm}>\mathrm{RH}-\mathrm{EC} / \mathrm{E}$ E100 (1:4) $500 \mathrm{rpm}>\mathrm{RH}-\mathrm{EC} / \mathrm{E}$ E100 (1:4) $300 \mathrm{rpm}>\mathrm{RH}-\mathrm{EC}(1: 2.5) 500 \mathrm{rpm}>\mathrm{RH}-\mathrm{E}$ E $100(1: 2.5) 300 \mathrm{rpm}$. 
Singh et al., (2011) found that the percentage of yield of RH microspheres was in range of $82.88 \%$ to $88.45 \%$ and was found to be increased by decreasing E E100 concentration. While, Mastiholimath et al., (2007) found that the percentage of yield of $\mathrm{RH} / \mathrm{EC}$ microspheres was in range of $82 \%$ to $89.31 \%$

\section{Entrapment efficiency of RH microspheres}

Depending upon the drug to polymer ratio, the drug entrapment was found in the range of $47.5 \%$ to $79.3 \%$ as shown in table (2). The drug loading was found to decrease with increase in polymer concentration due to its higher viscosity which affects the diffusion coefficient of drug.

Punithe et al., (2010) formulated floating microspheres of RH with E E100 of ratio $1: 1$ to $1: 3$ and found that the entrapment efficiency was in the range $37.58+0.76$ to 75.79 $+1.56$

Kumar et al., (2012) formulated floating microspheres of RH with EC of ratio 1:1 to1:5 and found the entrapment efficiency to be in the range $69.68+1.53$ to $73.78+3.05$

The polymer ratio, polymer type and speed of rotation had variable effects on the entrapment efficiency of RH microspheres as shown in figures (1-4)

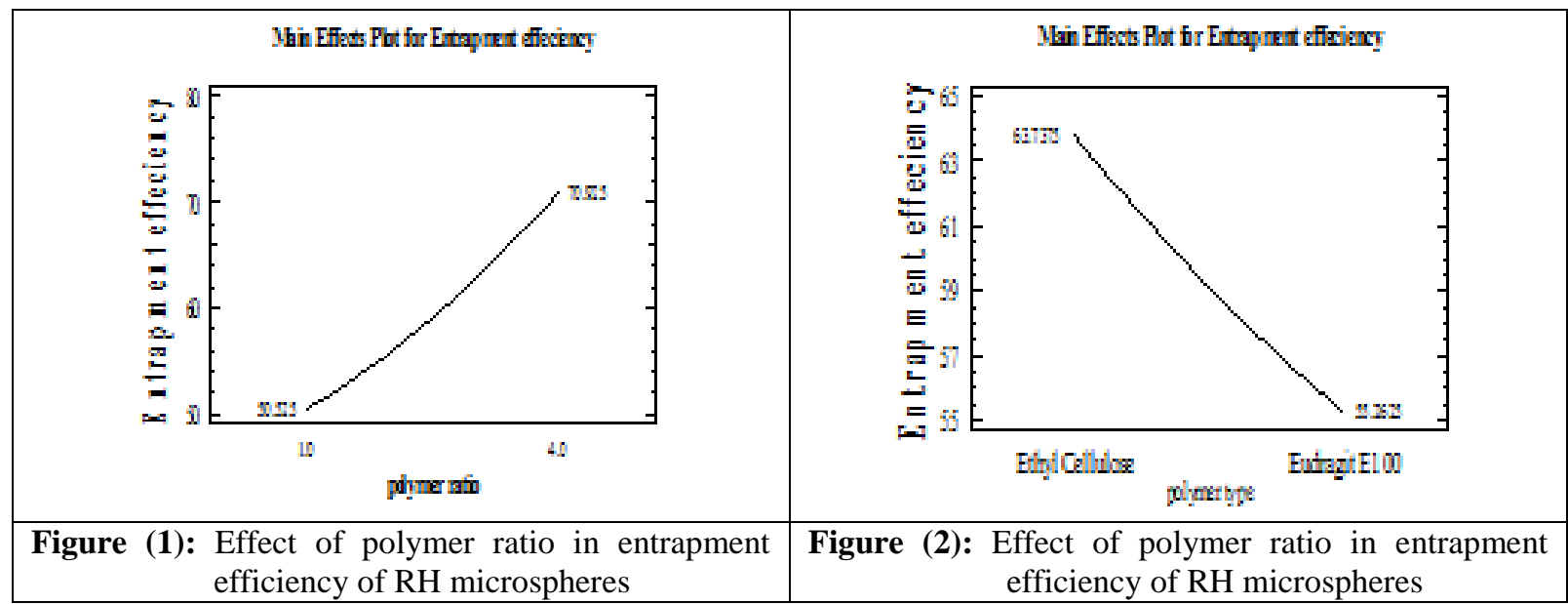

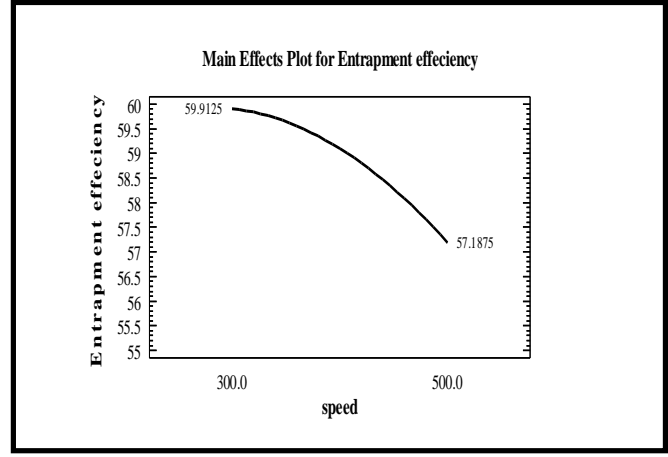

Figure (3): Effect of speed of rotation on entrapment efficiency of RH microspheres

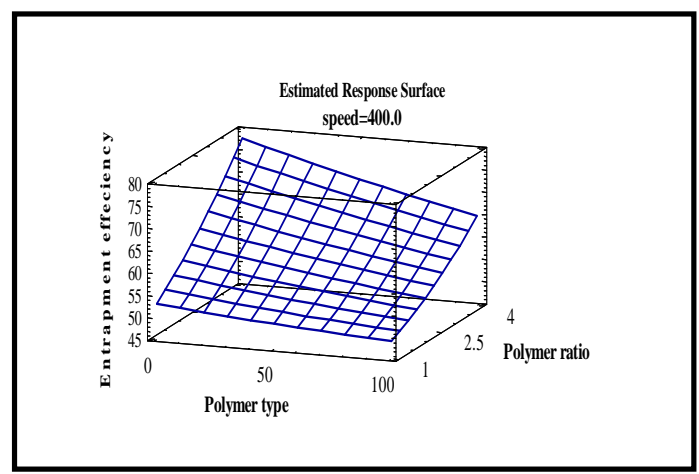

Figure (4): Estimated response surface on entrapment efficiency of RH microspheres

\section{Micromeritic properties of RH microspheres}

The prepared RH microspheres were studied for their micromeritic properties, including the angle of repose, bulk and tapped densities, Hausner ratio, and compressibility percent. 


\section{a- Angle of repose $(\theta)$}

The angle of repose was found to affect the flowability of the particles or granules. The values less than $20^{\circ}$ exhibit excellent flowability; the values between 20 and $30^{\circ}$ show good flowability; the values between 30 and $34^{\circ}$ exhibit passable flowability ; while the values above $34^{\circ}$ show very poor flowability (Bhowmik et al., 2009)

The values of angle of repose of prepared $\mathrm{RH}$ formulae ranged from $19.8^{\circ}$ to $29.14^{\circ}$ which gives indication that microencapsulation is a good method for improving the flowability.

Concerning the data obtained for the angle of repose for the prepared $\mathrm{RH}$ microspheres See table (3), it was found that R HCl - E E 100 (1:4) $400 \mathrm{rpm}$ showed the best value $\left(19.8^{\circ}\right)$ with excellent flowability while formula $\mathrm{R} \mathrm{HCl}-\mathrm{EC} / \mathrm{E} \mathrm{E} 100$ (1:1) $500 \mathrm{rpm}$ showed the worst value $\left(29.14^{\circ}\right)$ with good flowability.

Marabathuni et al., (2012) observed that the angle of repose of RH microspheres ranged from $22.83^{\circ} \pm 1.71$ with excellent flowability to $27.75^{\circ} \pm 3.39$ with fairly passable flowability.

So, the RH formulae can be arranged in descending manner as follows: RH-EC/E E100(1:1)500rpm > RH-E E100 (1:1) $400 \mathrm{rpm}>$ RH-E E100 (1:2.5) $500 \mathrm{rpm}>$ RH-EC (1:1) $400 \mathrm{rpm}>$ RH-EC/E E100 (1:1) $300 \mathrm{rpm}>$ RH-EC/E E100 (1:2.5) $400 \mathrm{rpm}>$ RH-EC $(1: 2.5) 500 \mathrm{rpm}>$ RH-E E100 (1:2.5) $300 \mathrm{rpm}>$ RH-EC100 (1:2.5) $300 \mathrm{rpm}>$ RH-E E100 (1:4) $400 \mathrm{rpm}>\mathrm{RH}-\mathrm{EC} / \mathrm{E}$ E100(1:4)500rpm> RH-EC/E E100(1:4)400rpm > RH-EC (1:4)400rpm which show excellent flowability.

\section{b- The bulk and tap densities}

The flow properties of the microspheres were investigated by measuring the bulk density, tapped density and Carr's index (Sahoo et al., 2005a; Sahoo et al., 2005b). Both the bulk and tapped densities were determined with equations described before, as illustrated in table (3). The mean values of both bulk and tapped densities were used to calculate both Hausner ratio and compressibility percent by applying the equations described above. These two parameters are related to the flow properties of the prepared microspheres.

\section{c- The Hausner ratio}

The value of the Hausner ratio was found to give indication about the flow properties of microspheres as shown in table (3). The values $<1.25$ indicate better flowability than values $>1.25$ (Bhowmik et al., 2009).According to the data obtained for Hausner ratio for the prepared RH microspheres, it was found that RH - EC (1:4) 400 rpm showed the best value (1.11) while formula RH - EC/E E100 (1:1) $500 \mathrm{rpm}$ showed the worst value (1.22).

So, the RH formulae can be arranged in descending manner as follows: RH-EC/E E100(1:1)500rpm > RH-E E100 (1:1) $400 \mathrm{rpm}>$ RH-E E100 (1:2.5) $500 \mathrm{rpm}>$ RH-EC (1:1) $400 \mathrm{rpm}>$ RH-EC/E E100 (1:1) $300 \mathrm{rpm}>$ RH-EC/E E100 (1:2.5) $400 \mathrm{rpm}>$ RH-EC $(1: 2.5) 500 \mathrm{rpm}>$ RH-E E100 (1:2.5) $300 \mathrm{rpm}>$ RH-EC100 (1:2.5) $300 \mathrm{rpm}>$ RH-E E100 (1:4) $400 \mathrm{rpm}>\mathrm{RH}-\mathrm{EC} / \mathrm{E}$ E100(1:4)500rpm> RH-EC/E E100(1:4)400rpm > RH-EC (1:4)400rpm which show excellent flowability.

\section{d- Compressibility \% (Carr's index)}

Compressibility percent is indirectly related to the relative flow rate, a compressible material will be less flowable. The value of the compressibility percent was found to affect the flow properties of the microspheres. The values between 5 and 12 show excellent flowability; the values between 12 and 16 exhibit good flowability; the values between 18 and 21 show fair passable flowability; the values between 23 and 35 exhibit poor flowability; while the values between 33 and 38 exhibit very poor flowability (Bhowmik $\boldsymbol{e t}$ al., 2009)

In the present study, the maximum compressibility percent for the tested $\mathrm{RH}$ formulae was $18.51 \%$ for formula RH - EC/E E100 (1:1) $500 \mathrm{rpm}$ which indicate fair 
passable flowability and the minimum one was $10 \%$ for formula RH - EC (1:4) $400 \mathrm{rpm}$ which indicate excellent flowability, See table (3).

So, the emulsion solvent evaporation technique employed in the present study produced spherical particles with relatively good flowability. Figure (5)

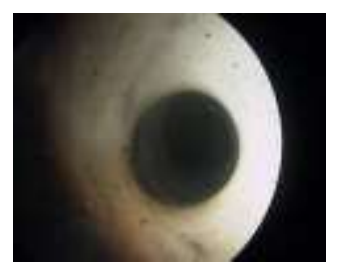

(a)

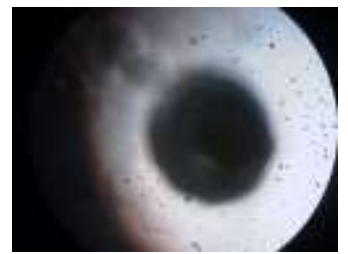

(e)

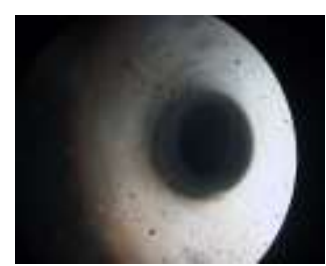

(b)

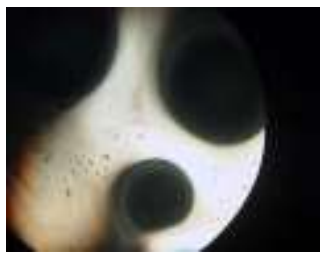

(f)

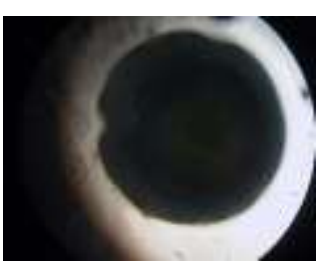

(c)

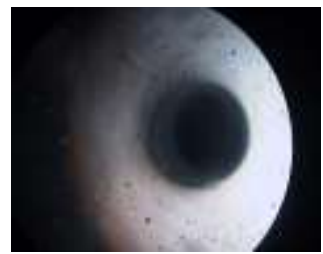

(g)

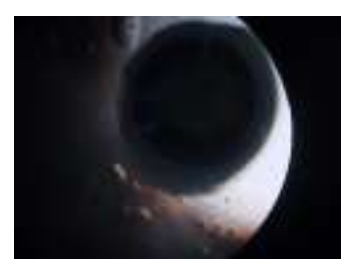

(d)

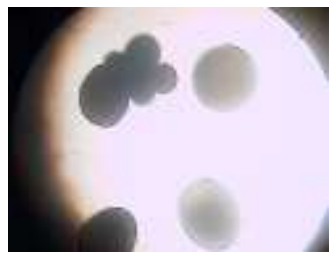

(h)

Figure (5): Optical photos of prepared RH microspheres

(a)RH - EC (1:1) $400 \mathrm{rpm}$, (b) RH - EC/E E100 (1:4) $500 \mathrm{rpm}$,(c) RH-EC/E E100 (1:4) 300rpm, (d) RH - EC (1:4) $400 \mathrm{rpm}$, (e) RH - EC (1:2.5) $300 \mathrm{rpm}$,(f) RH - EC/E E 100 (1:2.5), (g) RH - E E 100 (1:2.5) 300 rpm,(h) RH-E E100(1:1)400 rpm

By combining the rank order of the production yields, the drug contents and the micromeritic properties of prepared $\mathrm{RH}$ formulae in table (4), it was found that the best formula was RH-EC (1:4) $400 \mathrm{rpm}$ and the worst one was RH-EC/E E100 (1:1) 500rpm.

Table (2): Production yield and entrapment efficiency of RH microspheres

\begin{tabular}{|l|c|c|}
\hline \multicolumn{1}{|c|}{ Formula No } & $\begin{array}{c}\text { Production yield \% } \\
\text { (PY) }\end{array}$ & $\begin{array}{c}\text { Entrapment efficiency } \\
\text { \% (EE) }\end{array}$ \\
\hline RH - EC (1:2.5) 300 rpm & 86.06 & 62.1 \\
\hline RH - EC/E E 100 (1:2.5) 400 rpm & 98.688 & 59.1 \\
\hline RH - EC/E E 100 (1:2.5) 400 rpm & 98.688 & 59.1 \\
\hline RH - EC (1:1) 400 rpm & 77.88 & 53.9 \\
\hline RH - E E 100 (1:1) 400 rpm & 60.66 & 47.5 \\
\hline RH - E E 100 (1:2.5) 500 rpm & 86.35 & 55.4 \\
\hline RH - EC/E E100 (1:4) 500 rpm & 96.66 & 66 \\
\hline RH - EC/E E100 (1:1) 300 rpm & 87.06 & 50.8 \\
\hline RH - E E 100 (1:4) 400 rpm & 85.58 & 63.8 \\
\hline RH - E E 100 (1:2.5) 300 rpm & 90.35 & 56.5 \\
\hline RH - EC/E E100 (1:1) 500 rpm & 72.34 & 49.6 \\
\hline RH - EC/E E100 (1:4) 300 rpm & 96.466 & 74.3 \\
\hline RH - EC (1:4) 400 rpm & 87.8 & 79.3 \\
\hline RH - EC/EE 100 (1:2.5) 400 rpm & 98.688 & 59.1 \\
\hline RH - EC (1:2.5) 500 rpm & 94.71 & 61.8 \\
\hline
\end{tabular}


Table (3): Angle of repose, Bulk and Tapped densities of RH microspheres

\begin{tabular}{|l|c|c|c|c|c|}
\hline \multicolumn{1}{|c|}{ Formula No } & $\begin{array}{c}\text { Angle of } \\
\text { repose } \\
(\mathbf{\theta})(\mathbf{A R})\end{array}$ & $\begin{array}{c}\text { Bulk density } \\
\left(\mathbf{g m} / \mathbf{c m}^{3}\right)\end{array}$ & $\begin{array}{c}\text { Hausner } \\
\text { ratio (HR) }\end{array}$ & $\begin{array}{c}\text { Carr's } \\
\text { index (CI) }\end{array}$ & $\begin{array}{c}\text { Tapped } \\
\text { density } \\
\left(\mathbf{g m} / \mathbf{c m}^{3}\right)\end{array}$ \\
\hline RH - EC (1:2.5) 300 rpm & 23.14 & $0.525 \pm 0.005$ & 1.161 & 13.88 & $0.610 \pm 0.002$ \\
\hline RH - EC/E E 100 (1:2.5) 400 rpm & 24.05 & $0.489 \pm 0.002$ & 1.184 & 15.55 & $0.579 \pm 0.001$ \\
\hline RH - EC/E E 100 (1:2.5) 400 rpm & 24.05 & $0.489 \pm 0.002$ & 1.184 & 15.55 & $0.579 \pm 0.001$ \\
\hline RH - EC (1:1) 400 rpm & 28 & $0.450 \pm 0.001$ & 1.190 & 16 & $0.536 \pm 0.001$ \\
\hline RH - E E 100 (1:1) 400 rpm & 22 & $0.325 \pm 0.003$ & 1.217 & 17.85 & $0.395 \pm 0.002$ \\
\hline RH - E E 100 (1:2.5) 500 rpm & 20.85 & $0.462 \pm 0.004$ & 1.2 & 16.66 & $0.555 \pm 0.002$ \\
\hline RH - EC/E E100 (1:4) 500 rpm & 23.7 & $0.557 \pm 0.003$ & 1.155 & 13.46 & $0.644 \pm 0.001$ \\
\hline RH - EC/E E100 (1:1) 300 rpm & 27.47 & $0.398 \pm 0.003$ & 1.185 & 15.62 & $0.472 \pm 0.002$ \\
\hline RH - E E 100 (1:4) 400 rpm & 19.8 & $0.531 \pm 0.004$ & 1.16 & 13.79 & $0.616 \pm 0.001$ \\
\hline RH - E E 100 (1:2.5) 300 rpm & 20.3 & $0.484 \pm 0.003$ & 1.16 & 14.28 & $0.564 \pm 0.001$ \\
\hline RH - EC/E E100 (1:1) 500 rpm & 29.14 & $0.363 \pm 0.001$ & 1.22 & 18.51 & $0.446 \pm 0.003$ \\
\hline RH - EC/E E100 (1:4) 300 rpm & 21.04 & $0.599 \pm 0.006$ & 1.125 & 11.11 & $0.674 \pm 0.002$ \\
\hline RH - EC (1:4) 400 rpm & 20.3 & $0.627 \pm 0.005$ & 1.11 & 10 & $0.696 \pm 0.001$ \\
\hline RH - EC/EE 100 (1:2.5) 400 rpm & 24.05 & $0.489 \pm 0.004$ & 1.184 & 15.55 & $0.579 \pm 0.002$ \\
\hline RH - EC (1:2.5) 500 rpm & 24.9 & $0.505 \pm 0.005$ & 1.176 & 15 & $0.594 \pm 0.002$ \\
\hline
\end{tabular}

Table (4): Total rank orders concerning the production yields, the entrapment efficiency and the micromeritics properties for $\mathrm{RH}$ microspheres

\begin{tabular}{|l|c|c|c|c|c|c|c|}
\hline \multirow{2}{*}{ Formula No. } & \multicolumn{4}{c|}{ Rank Orders } & \multicolumn{2}{c|}{$\begin{array}{c}\text { Total Rank } \\
\text { order }\end{array}$} \\
\cline { 2 - 9 } & (PY) & (EE) & (AR) & (HR) & (CI) & Value & RO \\
\hline RH - EC (1:2.5) 300 rpm & 11 & 5 & 5 & 5 & 5 & 31 & 5 \\
\hline RH - EC/E E 100 (1:2.5) 400 rpm & 1 & 7 & 8 & 8 & 8 & 32 & 6 \\
\hline RH - EC/E E 100 (1:2.5) 400 rpm & 1 & 7 & 8 & 8 & 8 & 32 & 6 \\
\hline RH - EC (1:1) 400 rpm & 13 & 12 & 12 & 12 & 12 & 49 & 11 \\
\hline RH - E E 100 (1:1) 400 rpm & 15 & 15 & 14 & 14 & 14 & 72 & 14 \\
\hline RH - E E 100 (1:2.5) 500 rpm & 10 & 11 & 13 & 13 & 13 & 60 & 13 \\
\hline RH - EC/E E100 (1:4) 500 rpm & 4 & 3 & 3 & 3 & 3 & 16 & 3 \\
\hline RH - EC/E E100 (1:1) 300 rpm & 9 & 13 & 11 & 11 & 11 & 55 & 12 \\
\hline RH - E E 100 (1:4) 400 rpm & 12 & 4 & 4 & 4 & 4 & 28 & 4 \\
\hline RH - E E 100 (1:2.5) 300 rpm & 7 & 10 & 6 & 6 & 6 & 35 & 10 \\
\hline RH - EC/E E100 (1:1) 500 rpm & 14 & 14 & 15 & 15 & 15 & 73 & 15 \\
\hline RH - EC/E E100 (1:4) 300 rpm & 5 & 2 & 2 & 2 & 2 & 13 & 2 \\
\hline RH - EC (1:4) 400 rpm & 8 & 1 & 1 & 1 & 1 & 12 & 1 \\
\hline RH - EC/EE 100 (1:2.5) 400 rpm & 1 & 7 & 8 & 8 & 8 & 32 & 6 \\
\hline RH - EC (1:2.5) 500 rpm & 6 & 6 & 7 & 7 & 7 & 33 & 9 \\
\hline
\end{tabular}

\section{In-vitro buoyancy of RH microspheres}

In vitro buoyancy studies reveal that, microspheres still continued to float without any apparent gelation, thus indicating that microspheres can exhibit excellent buoyancies. The relative density of the microspheres is higher at higher polymer concentrations. So, the microspheres having higher polymer concentrations were less buoyant than those with lower polymers concentrations. The formula RH - E100 (1:1) $400 \mathrm{rpm}$ showed highest buoyancy of $92 \pm 4.4 \%$ while the formula RH-EC/E E100 (1:4) 300rpm showed the lowest buoyancy of $72 \pm 1.9 \%$. Table(5)showed the percentage of buoyant microspheres over $12 \mathrm{hr}$. 
Table (5): Rank order of percentage of buoyant microspheres of RH microspheres over 12 $\mathrm{hr}$

\begin{tabular}{|c|c|c|}
\hline Formula No. & $\begin{array}{c}\text { \% of buoyant } \\
\text { microspheres over } \\
12 \mathrm{hr} \\
\end{array}$ & RO \\
\hline RH - EC $(1: 2.5) 300 \mathrm{rpm}$ & $79+2.2$ & 11 \\
\hline RH - EC/E E $100(1: 2.5) 400 \mathrm{rpm}$ & $83 \pm 2.5$ & 7 \\
\hline RH - EC/E E $100(1: 2.5) 400 \mathrm{rpm}$ & $83 \pm 3.3$ & 7 \\
\hline RH - EC (1:1) $400 \mathrm{rpm}$ & $90 \pm 4$ & 3 \\
\hline RH - E E $100(1: 1) 400 \mathrm{rpm}$ & $92 \pm 4.4$ & 1 \\
\hline RH - E E $100(1: 2.5) 500 \mathrm{rpm}$ & $86 \pm 3.9$ & 5 \\
\hline RH - EC/E E100 (1:4) $500 \mathrm{rpm}$ & $78 \pm 2.1$ & 12 \\
\hline RH - EC/E E100 (1:1) $300 \mathrm{rpm}$ & $88 \pm 2.3$ & 4 \\
\hline RH - E E 100 (1:4) 400 rpm & $75 \pm 2.2$ & 13 \\
\hline RH - E E $100(1: 2.5) 300 \mathrm{rpm}$ & $80 \pm 3.1$ & 10 \\
\hline RH - EC/E E100 (1:1) $500 \mathrm{rpm}$ & $91 \pm 2.7$ & 2 \\
\hline RH - EC/E E100 (1:4) $300 \mathrm{rpm}$ & $72 \pm 1.9$ & 15 \\
\hline RH - EC (1:4) $400 \mathrm{rpm}$ & $73 \pm 2.8$ & 14 \\
\hline RH - EC/EE $100(1: 2.5) 400 \mathrm{rpm}$ & $83 \pm 1.7$ & 7 \\
\hline $\mathrm{RH}-\mathrm{EC}(1: 2.5) 500 \mathrm{rpm}$ & $84 \pm 3.4$ & 6 \\
\hline
\end{tabular}

\section{In-vitro release of $\mathrm{RH}$ microspheres}

Microspheres behave like plastic materials (Ahmed et al., 2001). Dissolution started as the dissolution medium penetrated through the pores of the microspheres. Dissolution medium dissolved $\mathrm{RH}$ as it penetrated the microspheres wall. This produced a saturated drug solution inside the microspheres body. That resulted in a concentration gradient between the interior of the microspheres and the dissolution medium. As dissolution proceeded, the dissolved drug diffused out. In vitro drug release studies also showed a biphasic release pattern for all formulations with an initial brust effect as showed in figures (6-8).

$\mathrm{RH}$ is water soluble and its release was prolonged up to $12 \mathrm{hr}$. The release of RH was retarded due to the hydrophobic and insoluble nature of the polymer used .It was also observed that as the polymer ratio increased, the drug release was decreased as the increased density of the polymer matrix at higher polymer concentration resulted in an increased diffusional path length . This may decrease the overall drug release from the polymer matrix. Figures (12-14) showed the effect of polymer ratio on RH release after $2 \mathrm{hr}, 6 \mathrm{hr}$ and $12 \mathrm{hr}$. Furthermore, smaller microspheres were formed at lower polymer concentration and had a larger surface area exposed to dissolution medium, resulted in faster drug release which is good agreement with (Mastiholimath et al., 2008; Singh et al., 2011). The cumulative percentage of drug release after $12 \mathrm{hr}$ ranged from $53.1 \pm 1.35$ to $99.9 \pm 0.51$ for the formulae RH-EC (1:4) $400 \mathrm{rpm}$, RH-E E100(1:1)400 rpm respectively as showed in table(6).

The speed of rotation had a direct effect on the drug release as. showed on figures (9-11)

The polymer type either (EC or E E100 or mixture of the both) affected the release of $\mathrm{RH}$; as the release of drug from formulae prepared with E E100 was higher than formulae with EC as showed in figures (15-17) showed the effect of type of polymer on the release of RH after $2 \mathrm{hr}, 6 \mathrm{hr}$ and $12 \mathrm{hr}$. 
Figures (18-20) showed the multiple responses of polymer type, polymer ratio and speed of rotation on RH release after $2 \mathrm{hr}, 6 \mathrm{hr}$ and $12 \mathrm{hr}$.

Table (6): In-Vitro release of R H from hard gelatin capsules

\begin{tabular}{|c|c|c|c|c|c|c|c|c|}
\hline \multirow[t]{2}{*}{ Formula No } & \multicolumn{8}{|c|}{ \% drug released after the respective time intervals (hr) } \\
\hline & 1 & 2 & 3 & 4 & 6 & 8 & 10 & 12 \\
\hline RH - EC (1:2.5) $300 \mathrm{rpm}$ & $\begin{array}{c}18.9 \\
\pm 1.24 \\
\end{array}$ & $\begin{array}{c}41.4 \\
\pm 1.29 \\
\end{array}$ & $\begin{array}{c}43.2 \\
\pm 1.48 \\
\end{array}$ & $\begin{array}{c}45 \\
\pm 1.54 \\
\end{array}$ & $\begin{array}{c}47.7 \\
\pm 0.87 \\
\end{array}$ & $\begin{array}{c}50.4 \\
\pm 1.36 \\
\end{array}$ & $\begin{array}{c}52.2 \\
\pm 0.85 \\
\end{array}$ & $\begin{array}{r}54.9 \\
\pm 2.49 \\
\end{array}$ \\
\hline RH - EC/E E $100(1: 2.5) 400 \mathrm{rpm}$ & $\begin{array}{c}44.1 \\
\pm 0.94\end{array}$ & $\begin{array}{c}46.8 \\
\pm 0.83\end{array}$ & $\begin{array}{c}50.4 \\
\pm 1.28\end{array}$ & $\begin{array}{c}53.1 \\
\pm 0.72\end{array}$ & $\begin{array}{c}57.6 \\
\pm 1.26\end{array}$ & $\begin{array}{c}63 \\
\pm 1.59\end{array}$ & $\begin{array}{c}66.6 \\
\pm 1.64\end{array}$ & $\begin{array}{r}75.6 \\
\pm 1.58\end{array}$ \\
\hline RH - EC/E E $100(1: 2.5) 400 \mathrm{rpm}$ & $\begin{array}{c}44.1 \\
\pm 0.94\end{array}$ & $\begin{array}{c}46.8 \\
\pm 0.83\end{array}$ & $\begin{array}{c}50.4 \\
\pm 1.28\end{array}$ & $\begin{array}{c}53.1 \\
\pm 0.72\end{array}$ & $\begin{array}{c}57.6 \\
\pm 1.26\end{array}$ & $\begin{array}{c}63 \\
\pm 1.59\end{array}$ & $\begin{array}{c}66.6 \\
\pm 1.64\end{array}$ & $\begin{array}{r}75.6 \\
\pm 1.58\end{array}$ \\
\hline RH - EC (1:1) $400 \mathrm{rpm}$ & $\begin{array}{c}20.7 \\
\pm 1.63\end{array}$ & $\begin{array}{c}43.2 \\
\pm 1.27\end{array}$ & $\begin{array}{c}45 \\
\pm 1.58\end{array}$ & $\begin{array}{c}55.8 \\
\pm 1.94\end{array}$ & $\begin{array}{c}56.7 \\
\pm 1.75\end{array}$ & $\begin{array}{c}58.5 \\
\pm 0.98\end{array}$ & $\begin{array}{c}60.3 \\
\pm 0.42\end{array}$ & $\begin{array}{c}63 \\
\pm 0.62\end{array}$ \\
\hline RH - E E $100(1: 1) 400 \mathrm{rpm}$ & $\begin{array}{c}36 \\
\pm 2.21\end{array}$ & $\begin{array}{c}72 \\
\pm 1.24\end{array}$ & $\begin{array}{c}81 \\
\pm 1.99\end{array}$ & $\begin{array}{c}93.6 \\
\pm 1.79\end{array}$ & $\begin{array}{c}94.5 \\
\pm 1.45\end{array}$ & $\begin{array}{c}96.3 \\
\pm 2.29\end{array}$ & $\begin{array}{c}98.1 \\
\pm 0.84\end{array}$ & $\begin{array}{r}99.9 \\
\pm 0.51\end{array}$ \\
\hline RH- E E $100(1: 2.5) 500 \mathrm{rpm}$ & $\begin{array}{c}20.7 \\
\pm 1.26\end{array}$ & $\begin{array}{c}53.1 \\
\pm 1.75\end{array}$ & $\begin{array}{c}58.5 \\
\pm 1.45\end{array}$ & $\begin{array}{c}63 \\
\pm 1.46\end{array}$ & $\begin{array}{c}80.1 \\
\pm 0.76\end{array}$ & $\begin{array}{c}85.5 \\
\pm 2.45\end{array}$ & $\begin{array}{c}90 \\
\pm 1.25\end{array}$ & $\begin{array}{r}92.7 \\
\pm 1.92\end{array}$ \\
\hline RH - EC/E E100 (1:4) 500 rpm & $\begin{array}{c}44.1 \\
\pm 2.29\end{array}$ & $\begin{array}{c}45.9 \\
\pm 1.85\end{array}$ & $\begin{array}{c}49.5 \\
\pm 1.94\end{array}$ & $\begin{array}{c}51.3 \\
\pm 2.34\end{array}$ & $\begin{array}{c}53.1 \\
\pm 3.76\end{array}$ & $\begin{array}{c}54.9 \\
\pm 1.74\end{array}$ & $\begin{array}{r}61.2 \\
\pm 1.92\end{array}$ & $\begin{array}{c}74.7 \\
\pm 1.58\end{array}$ \\
\hline RH - EC/E E100 (1:1) $300 \mathrm{rpm}$ & $\begin{array}{c}45 \\
\pm 1.92\end{array}$ & $\begin{array}{c}48.6 \\
\pm 1.64\end{array}$ & $\begin{array}{c}51.3 \\
\pm 2.62\end{array}$ & $\begin{array}{c}54.9 \\
\pm 0.92\end{array}$ & $\begin{array}{c}62.1 \\
\pm 0.82\end{array}$ & $\begin{array}{c}68.4 \\
\pm 1.75\end{array}$ & $\begin{array}{c}70.2 \\
\pm 1.35\end{array}$ & $\begin{array}{c}77.4 \\
\pm 1.59\end{array}$ \\
\hline RH - E E $100(1: 4) 400$ rpm & $\begin{array}{c}36.9 \\
\pm 1.75\end{array}$ & $\begin{array}{c}39.6 \\
\pm 1.93\end{array}$ & $\begin{array}{c}41.4 \\
\pm 0.92\end{array}$ & $\begin{array}{c}44.1 \\
\pm 0.75\end{array}$ & $\begin{array}{c}45.9 \\
\pm 1.64\end{array}$ & $\begin{array}{r}48.6 \\
\pm 1.47\end{array}$ & $\begin{array}{c}53.1 \\
\pm 0.93\end{array}$ & $\begin{array}{c}59.4 \\
\pm 0.86\end{array}$ \\
\hline RH- E E $100(1: 2.5) 300 \mathrm{rpm}$ & $\begin{array}{c}40.5 \\
\pm 2.92\end{array}$ & $\begin{array}{c}47.7 \\
\pm 1.42\end{array}$ & $\begin{array}{c}56.7 \\
\pm 1.95\end{array}$ & $\begin{array}{c}59.4 \\
\pm 1.74\end{array}$ & $\begin{array}{c}72.9 \\
\pm 1.82\end{array}$ & $\begin{array}{c}84.6 \\
\pm 2.98\end{array}$ & $\begin{array}{c}85.5 \\
\pm 0.94\end{array}$ & $\begin{array}{c}87.3 \\
\pm 1.62\end{array}$ \\
\hline RH- EC/E E100 (1:1) 500 rpm & $\begin{array}{c}47.7 \\
\pm 1.83\end{array}$ & $\begin{array}{c}53.1 \\
\pm 1.95\end{array}$ & $\begin{array}{c}57.6 \\
\pm 2.52\end{array}$ & $\begin{array}{c}62.1 \\
\pm 0.82\end{array}$ & $\begin{array}{c}65.7 \\
\pm 1.72\end{array}$ & $\begin{array}{c}74.7 \\
\pm 2.92\end{array}$ & $\begin{array}{c}79.2 \\
\pm 1.62\end{array}$ & $\begin{array}{r}94.5 \\
\pm 0.82\end{array}$ \\
\hline RH- EC/E E100 (1:4) $300 \mathrm{rpm}$ & $\begin{array}{c}40.5 \\
\pm 1.45\end{array}$ & $\begin{array}{c}42.3 \\
\pm 1.96\end{array}$ & $\begin{array}{c}44.1 \\
\pm 1.74\end{array}$ & $\begin{array}{c}47.7 \\
\pm 1.27\end{array}$ & $\begin{array}{c}48.6 \\
\pm 0.65\end{array}$ & $\begin{array}{r}52.2 \\
\pm 2.92\end{array}$ & $\begin{array}{c}54.9 \\
\pm 0.47\end{array}$ & $\begin{array}{r}57.6 \\
\pm 1.52\end{array}$ \\
\hline RH- EC (1:4) $400 \mathrm{rpm}$ & $\begin{array}{c}32.4 \\
\pm 1.37\end{array}$ & $\begin{array}{c}34.2 \\
\pm 1.46\end{array}$ & $\begin{array}{c}39.6 \\
\pm 1.38\end{array}$ & $\begin{array}{c}42.3 \\
\pm 0.61\end{array}$ & $\begin{array}{c}44.1 \\
\pm 1.79\end{array}$ & $\begin{array}{c}45.9 \\
\pm 0.82\end{array}$ & $\begin{array}{c}50.4 \\
\pm 1.73\end{array}$ & $\begin{array}{c}53.1 \\
\pm 1.35\end{array}$ \\
\hline RH- EC/EE $100(1: 2.5) 400$ rpm & $\begin{array}{c}44.1 \\
\pm 0.94\end{array}$ & $\begin{array}{c}46.8 \\
\pm 0.83\end{array}$ & $\begin{array}{r}50.4 \\
\pm 1.28\end{array}$ & $\begin{array}{c}53.1 \\
\pm 0.72\end{array}$ & $\begin{array}{c}57.6 \\
\pm 1.26\end{array}$ & $\begin{array}{r}63 \\
\pm 1.59\end{array}$ & $\begin{array}{r}66.6 \\
\pm 1.64\end{array}$ & $\begin{array}{r}75.6 \\
\pm 1.58\end{array}$ \\
\hline RH- EC (1:2.5) $500 \mathrm{rpm}$ & $\begin{array}{c}19.8 \\
\pm 1.55\end{array}$ & $\begin{array}{c}42.3 \\
\pm 1.73\end{array}$ & $\begin{array}{c}46.8 \\
\pm 1.79\end{array}$ & $\begin{array}{c}48.6 \\
\pm 0.62\end{array}$ & $\begin{array}{c}50.4 \\
\pm 1.98\end{array}$ & $\begin{array}{c}53.1 \\
\pm 1.37\end{array}$ & $\begin{array}{c}54.9 \\
\pm 1.94\end{array}$ & $\begin{array}{c}60.3 \\
\pm 1.47\end{array}$ \\
\hline
\end{tabular}

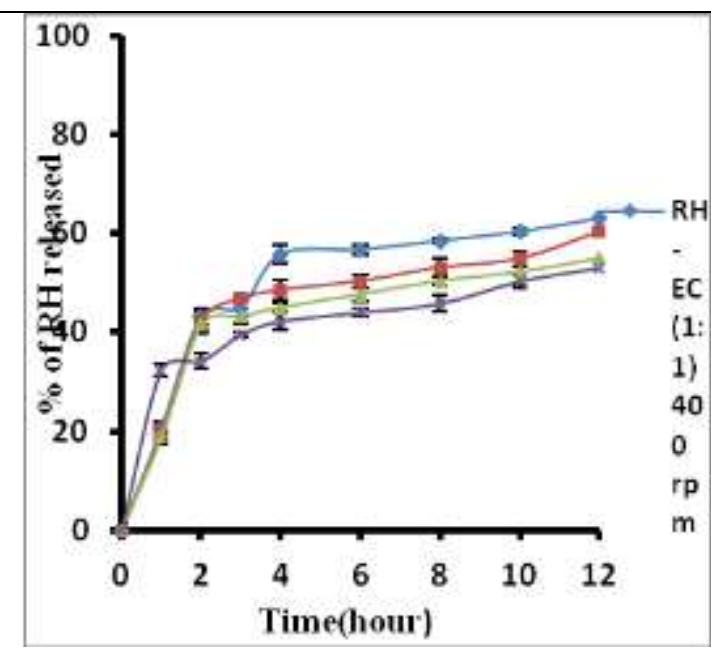

Figure (6): In-vitro release of RH from hard gelatin capsule using EC polymer

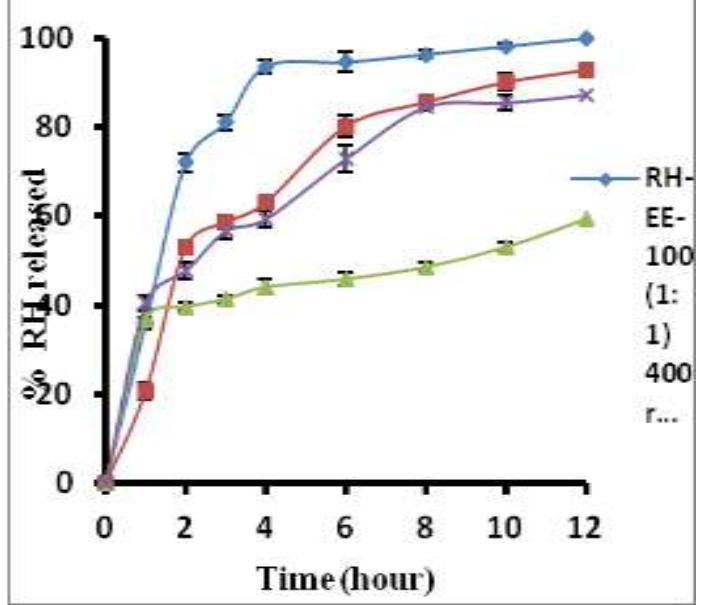

Figure (7): In-vitro release of RH from hard gelatin capsule using E E100 polymer 


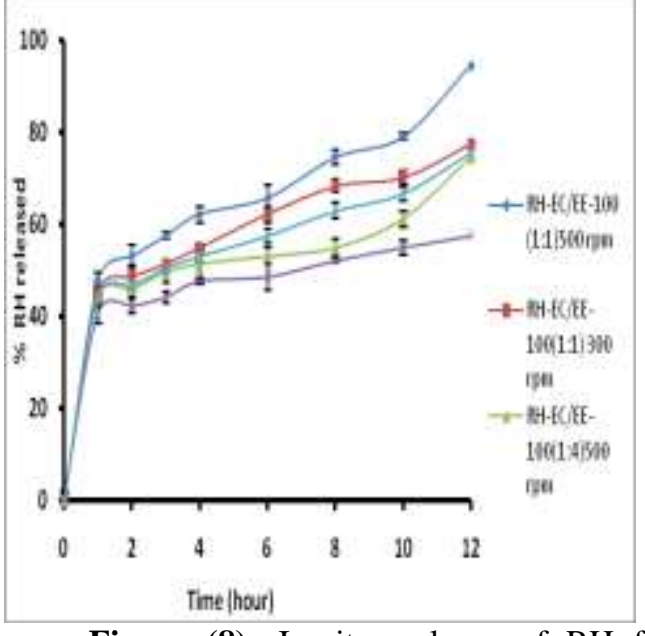

Figure (8): In-vitro release of RH from Figure (9): Effect of speed of rotation on RH release hard gelatin capsule using EC/EE 100 polymers

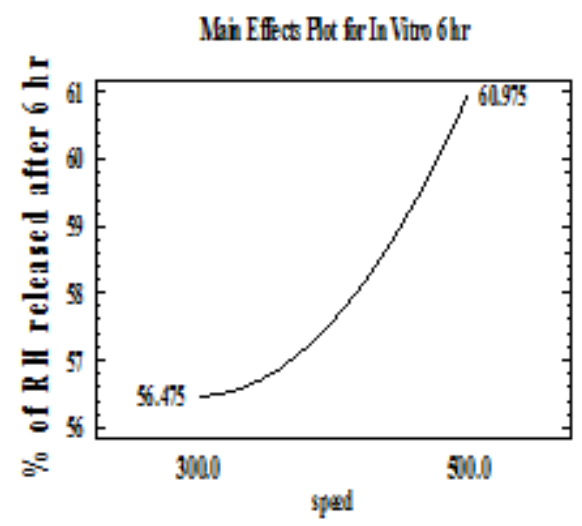

Figure (10): Effect of speed of rotation on $\mathrm{RH}$ release after $6 \mathrm{hr}$

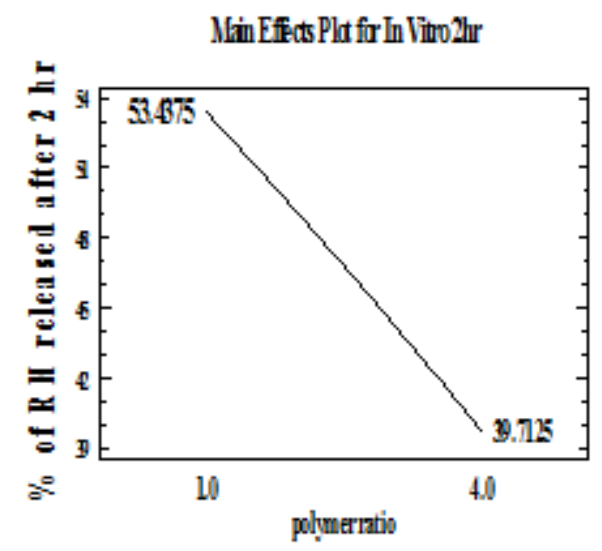

Figure (12): Effect of polymer ratio on $\mathrm{RH}$ release after $12 \mathrm{hr}$

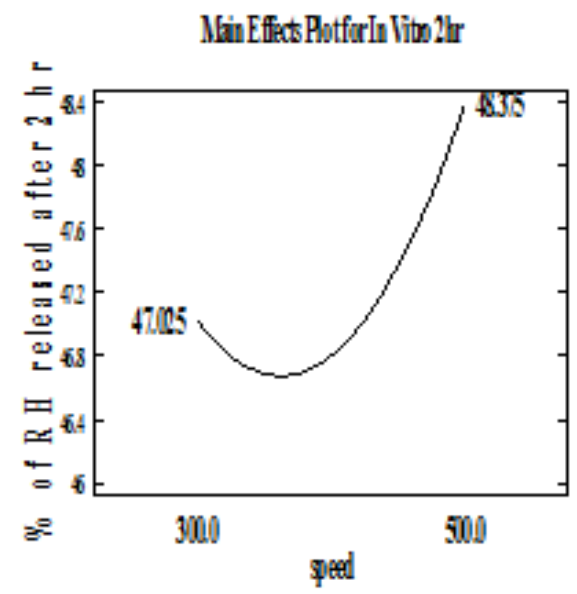
after 2

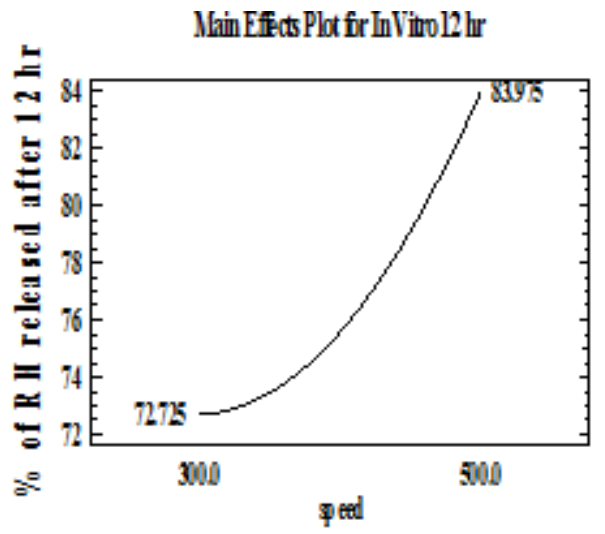

Figure (11): Effect of speed of rotation on RH release after $2 \mathrm{hr}$.

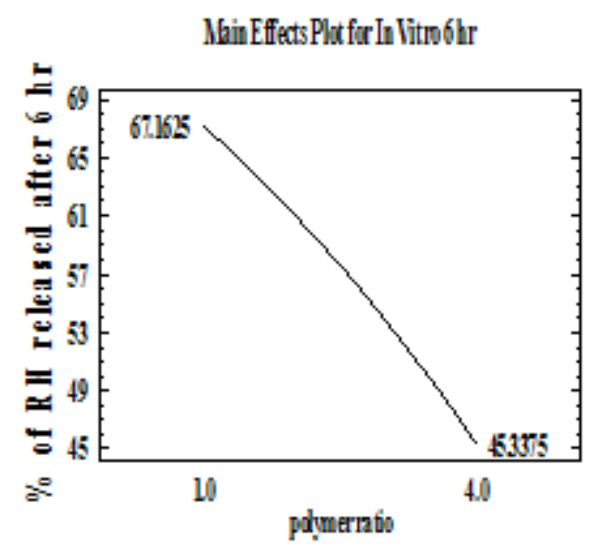

Figure (13): Effect of polymer ratio on $\mathrm{RH}$ release after $6 \mathrm{hr}$ 


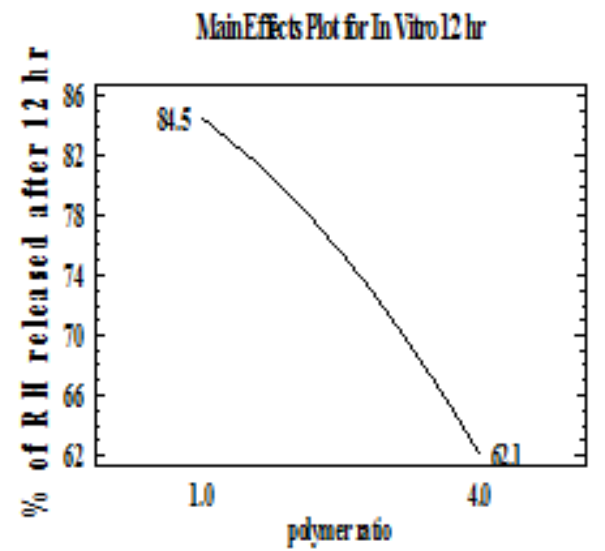

Figure (14): Effect of polymer ratio on RH release after $12 \mathrm{hr}$

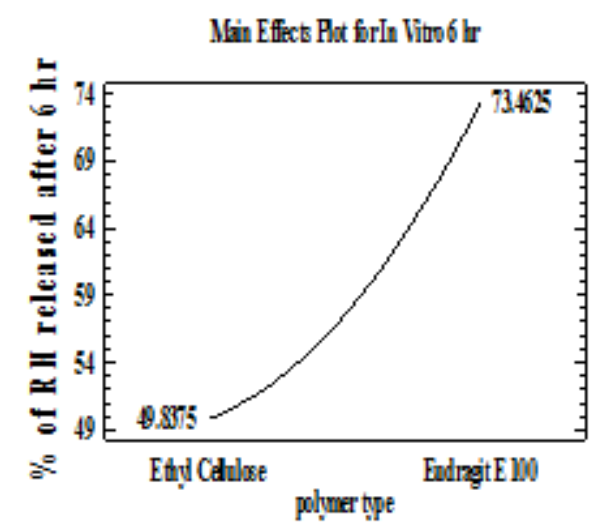

Figure (16): Effect of polymer type on RH release after $6 \mathrm{hr}$

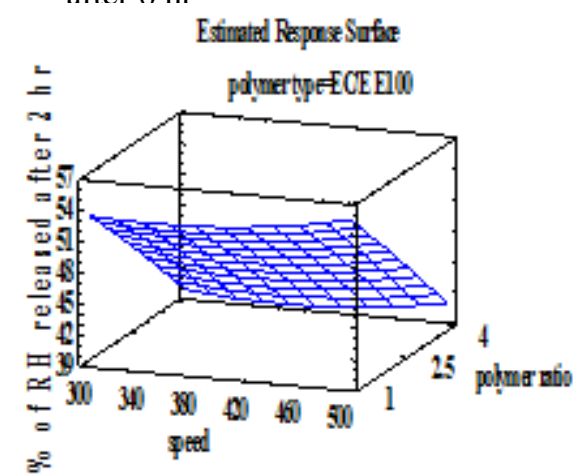

Figure (18): Estimated response surface on RH release after $2 \mathrm{hr}$

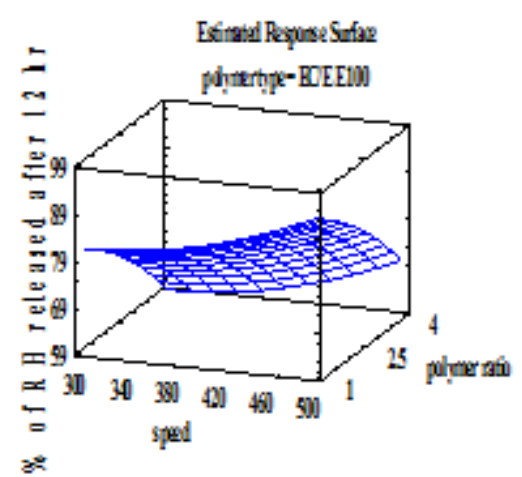

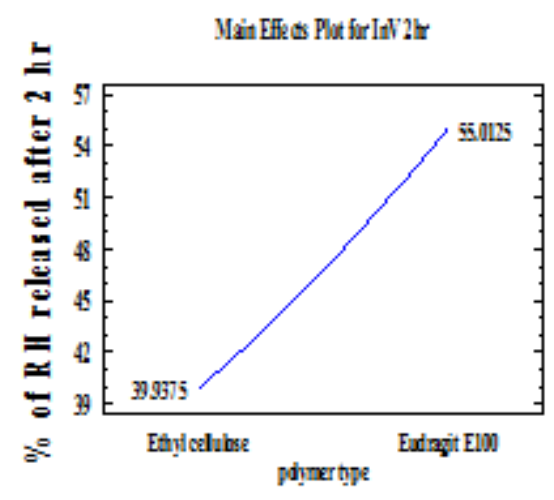

Figure (15): Effect of polymer type on RH release after $2 \mathrm{hr}$

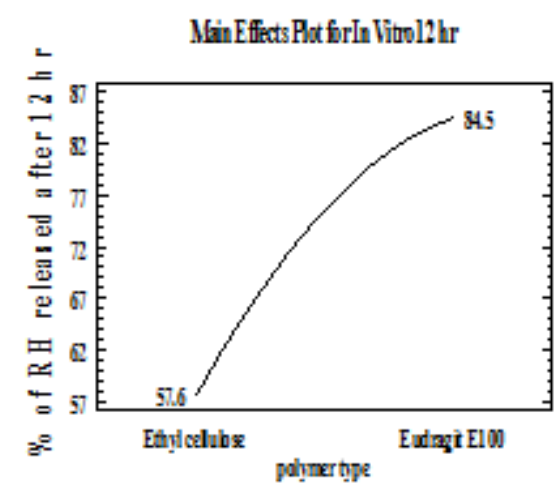

Figure (17): Effect of polymer type on RH release after $12 \mathrm{hr}$

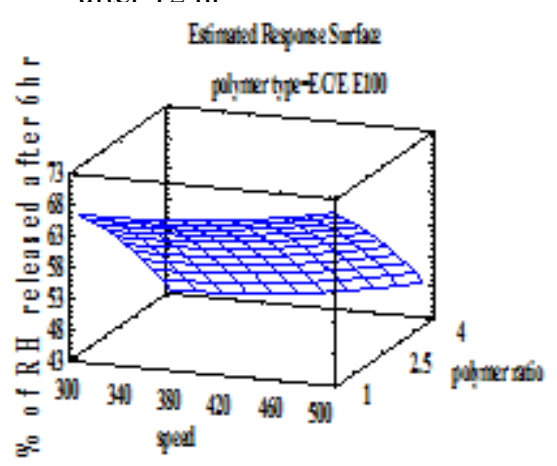

Figure (18): Estimated response surface on $\mathrm{RH}$ release after $6 \mathrm{hr}$

Figure (18): Estimated response surface on $\mathrm{RH}$ release after $12 \mathrm{hr}$ 


\section{CONCLUSION}

- The drug-polymer ratio, the type of polymer employed, and the speed of rotation have reasonable effects on the entrapment efficiency of the prepared $\mathrm{RH}$ microspheres

- The micromeritic properties of the prepared RH microspheres which include the angle of repose, bulk density, tapped density, Hauser ratio, and compressibility percent indicate that the produced spherical particles with relatively good flowability which could be easily filled in capsules or compressed in to tablets.

- In vitro release of RH microspheres from hard gelatin capsule was affected by polymer type, polymer ratio and speed of rotation.

- The percentage of buoyant microspheres ranged from 72 to92\% over $12 \mathrm{hr}$

- By combining the production yields, the entrapment efficiency, the micromeritic parameters and the in-vitro release of $\mathrm{RH}$ microspheres from hard gelatin capsules it was found that the best formulae in this study was RH-EC/E E100(1:2.5)400 rpm

\section{REFERENCES}

Ahmed, A.M.S., El-Say, K.M. and Fetouh, M.I., (2001): Effect of polymer on the formulation, micromeritic properties, in-vitro evaluation and stability testing on Ibuprofen microcapsules prepared by the emulsion solvent- evaporation technique, Az. J. Pharm. Sci., 28, 267-284.

Bhowmik, D., Chiranjib. B., Krishnakanth, Pankaj, R., Chandira, M., (2009): Fast dissolving tablet., J. Chem. and Pharm. Res., 1(1), 163-177.

El-Kamel, A., Al-Shora, D. H., and El-Sayed, Y. M., (2006): Formulation and pharmacodynamic evaluation of captopril sustained release microcapsules, J. Microencap., 23 (4), 389-404.

Brijesh, S.D., Avani F.A and Madhabhai M.P, (2004): Gastro retentive drug delivery system of ranitidine hydrochloride: formulation and in-vitro evaluation, AAPS Pharm. Sci. Tech.; 5(2), pp: 1-6.

Jayavadhan, P., Darshana .P and Jignyasha R., (2010): Formulation andevaluation of Propronolol hydrochloride-loaded carbopol934P/Ethyl cellulose muco adhesive microspheres. Iranian J.Pharm. Res.; 9(3), pp: 221-232

Kumar, H., Kymonil, k.m., Saraf, S.A., (2012): Gastro retentive Ethyl Cellulose Floating Microspheres containing Ranitidine hydrochloride, Int.J.of drug devolp.\&res. 4(2).

Kumar, V., Medina, M.L.R., Yang, D., (2002): Preparation, Characterization, and Tableting Properties of a New Cellulose-based Pharmaceutical Aid., Int. J. Pharm., 235 (1-2), 129-140.

Marabathuni, V.J., Deveswaran, r., Bharath, S., Basavaraj, B.V. and Madhavan, V., (2012): Design and optimization of multiparticulate gastroretentive delivery system of Ranitidine Hydrochloride,Int.J.of pharmaceutical science,4(2).

Mastiholimath, V.S., Dandagi, P.M., Gadad, A.P., Mathews, R., and Kulkarni, A.R., (2008): In vitro and in vivo evaluation of Ranitidine hydrochloride ethyl cellulose floating microparticles, J. of Microencap.,25(5):305-314(2008)

Punitha k., Khadhir, S., Ravichandiran, V., Umadevi, S.K., Vaijayanthi,V., Padmapriya, S., and Sureshkumar, S., (2010): Intragastric floating drug delivery system of Ranitidine hydrochloride: formulation and evaluation , Int.J. of pharm. And pharmaceu.Sci.2 (4). 
Rowe, R.C., Sheskey, R.J., and Weller, P.J., (2003): in "Handbook of Pharmaceutical Excipients", Rowe, R.C., Sheskey, R.J., and Weller, P.J., (eds.)., 4th ed., Royal Publishers, London, England

Sahoo, S.K., Mallick, A.A., Barik, B.B., and Senapati, P.C., (2005): Formulation and in vitro Evaluation of Eudragit ${ }^{\circledR}$ Microspheres of Stavudine. Trop. J. Pharm. Res., 4, 369-375.

Sahoo, S.K., Mallick, A.A., Barik, B.B., and Senapati, P.C., (2007): Preparation and in vitro evaluation of ethylcellulose microspheres containing stavudine by the double emulsion method. Pharmazie, 62, 117-121.

Sajeev, C., Vinay, G., Archna, R., and Saha, R.N., (2002): Oral controlled release formulation of diclofenac sodium by microencapsulation with ethylcellulose, J. Microencapsul., 19, 753- 760.

Singh, V. and Chaudhary, K.A., (2011): Preparation of Eudragit E100 microspheres by modified solvent evaporation method,Acta Poloniae Pharmaceutica Drug Research, 68(6)975-980.

Staniforth, J., (2002): in "Powder flow In Pharmaceutics", Aulton M.E., (ed.). $2^{\text {nd }}$ Ed., Churchill Livingstone, London, P. 207.

Tayade, P.T., and Kale, R.D., Encapsulation of water- insoluble drugs by a cross-linking technique: Effect of process and formulation variables on encapsulation efficiency, particle size, and in vitro dissolution rate, Pharm. Sci., 6, 12 (2)

صياغة وتقييم الكريات الاقيقة الطافية لعقار رانتيدين ايدروكلوريد لاعطاء عقار منتظم الاتاحة

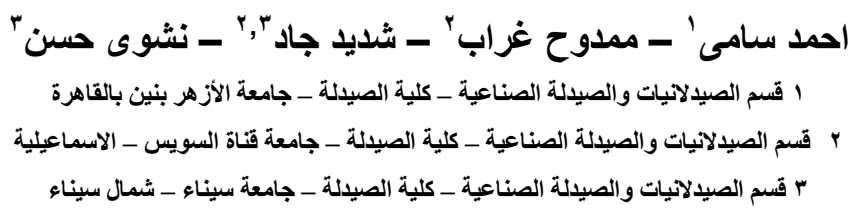

الهدف من هذه البحث هو تصميم وصياغة هيدروكلوريد رانيتيدين (RH) في صورة كريات دقيقة طافيه

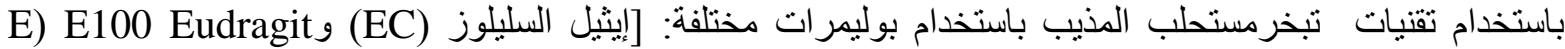

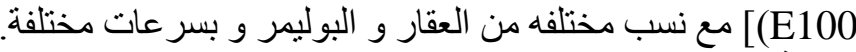

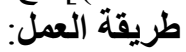

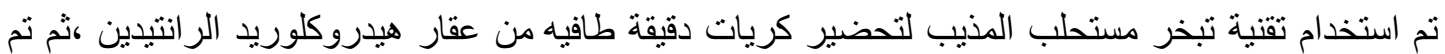

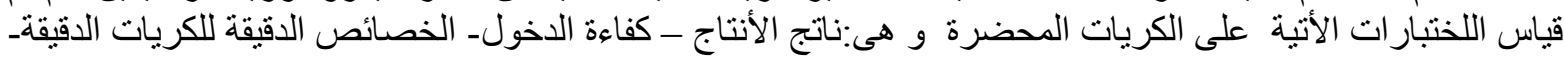

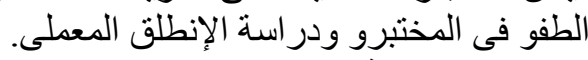

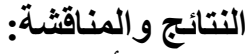

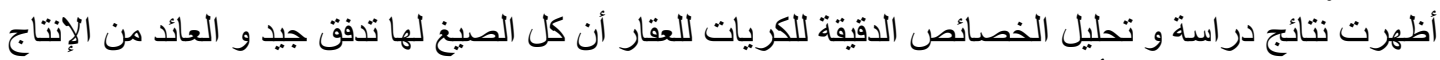

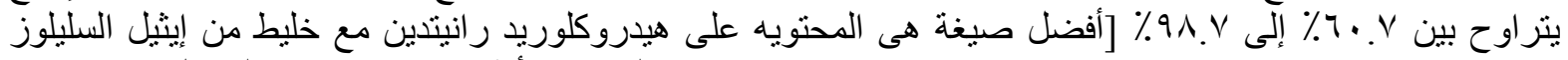

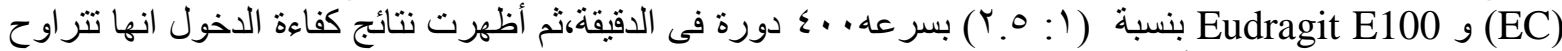

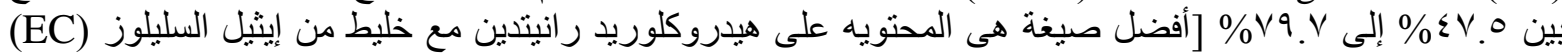

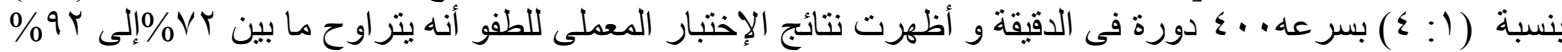

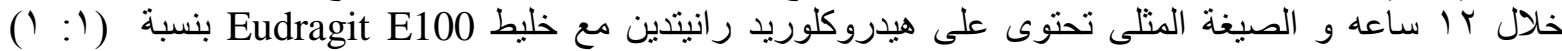

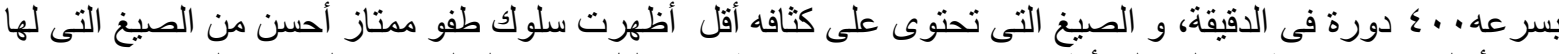

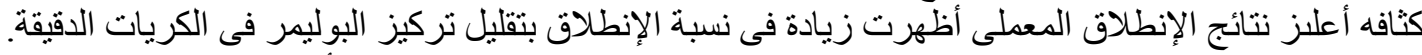

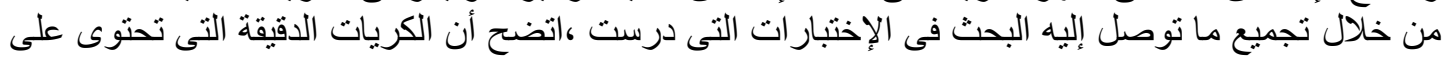

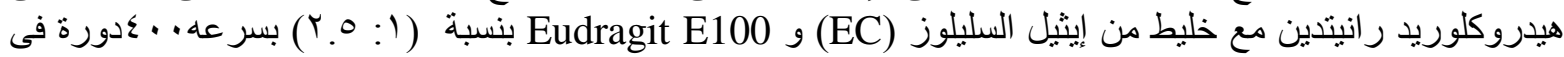

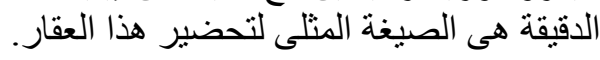

